\title{
Cost-effectiveness comparison of lamivudine plus adefovir combination treatment and nucleos $(t)$ ide analog monotherapies in Chinese chronic hepatitis B patients
}

\author{
This article was published in the following Dove Press journal: \\ Drug Design, Development and Therapy \\ I March 2016 \\ Number of times this article has been viewed
}

\section{Chi Zhang* \\ Weixia Ke* \\ Li Liu \\ Yanhui Gao \\ Zhenjiang Yao \\ Xiaohua Ye \\ Shudong Zhou \\ Yi Yang}

Department of Epidemiology and Biostatistics, School of Public Health, Guangdong Pharmaceutical University, Guangzhou, Guangdong, People's Republic of China

*These authors contributed equally to this work
Correspondence: Yi Yang

Department of Epidemiology and

Biostatistics, School of Public Health,

Guangdong Pharmaceutical University, Jianghai Avenue 283, Guangzhou 510310, Guangdong, People's Republic of China

Tel +86203405 5802

Fax +86203405 5355

Email yangyigz@163.com
Background/aim: Lamivudine (LAM) plus adefovir (ADV) combination therapy is clinically efficacious for treating chronic hepatitis $\mathrm{B}(\mathrm{CHB})$ patients in China, but no pharmacoeconomic evaluations of this strategy are available. The aim of this study was to examine the cost-effectiveness of LAM plus ADV combination treatment compared with five other nucleos(t)ide analog monotherapies (LAM, ADV, telbivudine [TBV], entecavir [ETV], and tenofovir [TDF]).

Methods: To simulate the lifetime (40-year time span) costs and quality-adjusted life-years (QALYs) for different therapy options, a Markov model that included five initial monotherapies and LAM plus ADV combination as an initial treatment was developed. Two kinds of rescue combination strategies (base-case: LAM + ADV then ETV + ADV; alternative: direct use of $\mathrm{ETV}+\mathrm{ADV}$ ) were considered separately for treating patients refractory to initial therapy. Oneway and probabilistic sensitivity analyses were used to explore model uncertainties.

Results: In base-case analysis, ETV had the lowest lifetime cost and served as the reference therapy. Compared to the reference, LAM, ADV, and TBV had higher costs and lower efficacy, and were completely dominated by ETV. LAM plus ADV combination therapy or TDF was more efficacious than ETV, but also more expensive. Although the incremental cost-effectiveness ratios of combination therapy or TDF were both higher than the willingness-to-pay threshold of \$20,466/QALY gained for the reference treatment, in an alternative scenario analysis LAM plus ADV combination therapy would be the preferable treatment option.

Conclusion: ETV and LAM plus ADV combination therapy are both cost-effective strategies for treating Chinese CHB patients.

Keywords: cost-effectiveness, chronic hepatitis B, nucleos(t)ide analog, combination treatment

\section{Introduction}

Chronic hepatitis B (CHB) is a serious public health problem that affects more than 240 million people worldwide. Each year, approximately 650,000 patients die from hepatic decompensation, cirrhosis, and hepatocellular carcinoma (HCC) caused by hepatitis B chronic infection. ${ }^{1}$ According to a national seroepidemiological survey, there are an estimated 93 million chronic hepatitis B virus (HBV) carriers in China, and among them 30 million are CHB patients. ${ }^{2}$ Recently, HBV DNA levels were found to be an important risk factor associated with the development of advanced liver diseases in CHB patients. ${ }^{3}$ Thus, the current primary goal of antiviral therapy is to delay or prevent progression of liver diseases by suppressing HBV DNA replication to the lowest possible levels. ${ }^{2,4-6}$ 
Current nucleos(t)ide analogs to treat CHB in China include lamivudine (LAM), adefovir (ADV), telbivudine (TBV), entecavir (ETV), and tenofovir (TDF), although high resistance rates to LAM, ADV, and TBV have hampered the therapeutic effectiveness of these drugs. ${ }^{7-10}$ Because of superior efficacy and markedly low resistance, several guidelines have recommended ETV and TDF as first-line options for treating CHB. ${ }^{4-6}$ However, despite their effectiveness, the high daily cost of ETV and TDF therapy may present a substantial economic burden for $\mathrm{CHB}$ patients in the long-term. Recent evidence from research suggested that in the absence of cross-resistance to LAM and ADV, ${ }^{11}$ LAM plus ADV combination therapy could be used for treating CHB patients, and might in turn reduce drug-associated resistance, ${ }^{12}$ especially for LAM-resistant or liver-transplant patients. ${ }^{13-16}$ A meta-analysis comparing the efficacy of LAM plus ADV combination therapy and ETV monotherapy for CHB patients showed that combination therapy generates a much higher virologic response rate and lower drug resistance than ETV monotherapy for up to 96 weeks. ${ }^{17}$ In addition, previous clinical experiences or studies demonstrated the excellent effectiveness of an initial combination strategy for treating CHB patients. ${ }^{18-24}$ In China, initial use of LAM plus ADV combination therapy has been recommended for treating CHB patients with high viral loads ${ }^{25}$ and appears to be a promising and superior option for $\mathrm{CHB}$ patients.

Considering the prolonged nature of $\mathrm{CHB}$, the long-term cost of combination therapy should be taken into account. However, to our knowledge, there is no study that compares the cost-effectiveness of LAM plus ADV combination treatment with current available nucleos(t)ide monotherapies used to treat Chinese CHB patients. Therefore, the objective of this study was to evaluate the long-term cost-effectiveness of LAM plus ADV combination treatment compared with the five nucleos(t)ide monotherapies (LAM, ADV, TBV, ETV, and TDF) currently used for CHB patients.

\section{Methods}

\section{Treatment options}

Six different initial strategies for $\mathrm{CHB}$ patients were considered: LAM monotherapy $(100 \mathrm{mg} / \mathrm{d})$, ADV monotherapy $(10 \mathrm{mg} / \mathrm{d})$, TBV monotherapy $(600 \mathrm{mg} / \mathrm{d})$, ETV monotherapy $(0.5 \mathrm{mg} / \mathrm{d})$, TDF monotherapy (300 mg/d), and combination therapy using LAM $(100 \mathrm{mg} / \mathrm{d})$ plus ADV $(10 \mathrm{mg} / \mathrm{d}) .^{2}$ After a 1-year cycle of treatment, patients with detectable serum HBV DNA ( $>300-400$ copies $/ \mathrm{mL}$ ) were considered as nonresponders, and these patients, along with HBV drug-resistant patients, received rescue therapies. In order to simplify the model, two rescue combination strategies were considered separately. In base-case analysis, the most common rescue strategy of $\operatorname{LAM}(100 \mathrm{mg} / \mathrm{d})$ plus ADV $(10 \mathrm{mg} / \mathrm{d})$ combination treatment was first used for patients whose initial therapy failed, and then the more potent combination of ETV $(1 \mathrm{mg} / \mathrm{d})$ and ADV $(10 \mathrm{mg} / \mathrm{d})$ was administered to patients who developed drug resistance or showed no response to prior rescue strategies. The direct combination of ETV $(1 \mathrm{mg} / \mathrm{d})$ and ADV $(10 \mathrm{mg} / \mathrm{d})$ was considered in an alternative scenario analysis. ${ }^{15}$

\section{Markov model}

A Markov model (compiled using TreeAge Pro Suite 2014 Program Software; TreeAge Software, Inc., Williamstown, MA, USA) was used to simulate the disease progression of CHB patients and to evaluate lifetime costs, life years saved (LYS), and quality-adjusted life years (QALYs) that were associated with LAM plus ADV combination treatment and the five nucleos(t)ide analogs. A Chinese cohort of 35-year-old hepatitis B e antigen ( $\mathrm{HBe} A g$ )-positive or -negative patients with $\mathrm{CHB}$ was entered into the model. Patients were HBV DNA positive, and alanine transaminase level was elevated, but there were no related liver diseases. The life expectancy of Chinese people is 75 years, and thus the lifetime horizons of this model were set at 40 years. ${ }^{26}$ Based on previous studies, ${ }^{27,28}$ the model consisted of nine mutually-exclusive disease states, including $\mathrm{CHB}$, virologic response, virologic resistance, compensated cirrhosis, decompensated cirrhosis, HCC, liver transplantation, post-liver transplantation, and death (Figure 1). Patients entered the model from the CHB state and could enter into the next state or remain in the same state after each 1-year cycle. Previous studies showed a significant association between serum HBV DNA levels and disease progression, ${ }^{3}$ and thus patients who had HBV DNA levels as low as $300-400$ copies/ $\mathrm{mL}$ might have a decreased risk of progressing to advanced liver disease. ${ }^{2,29}$ Similarly, in our model, the annual transition rates between disease states were mostly dependent on HBV DNA level..$^{30}$ Compared with nonvirologic responders (HBV DNA load $>300-400$ copies/mL) and virologicresistant patients, patients categorized as being in a virologic response state (HBV DNA load $<300-400$ copies $/ \mathrm{mL}$ ) were less likely to progress to cirrhosis and HCC. ${ }^{3,27}$ Beyond the first year, a discount rate of 5\% was applied to adjust costs and effectiveness.

\section{Clinical data}

The disease transition rates, treatment-induced virologic response, and resistance rates were all derived from studies 


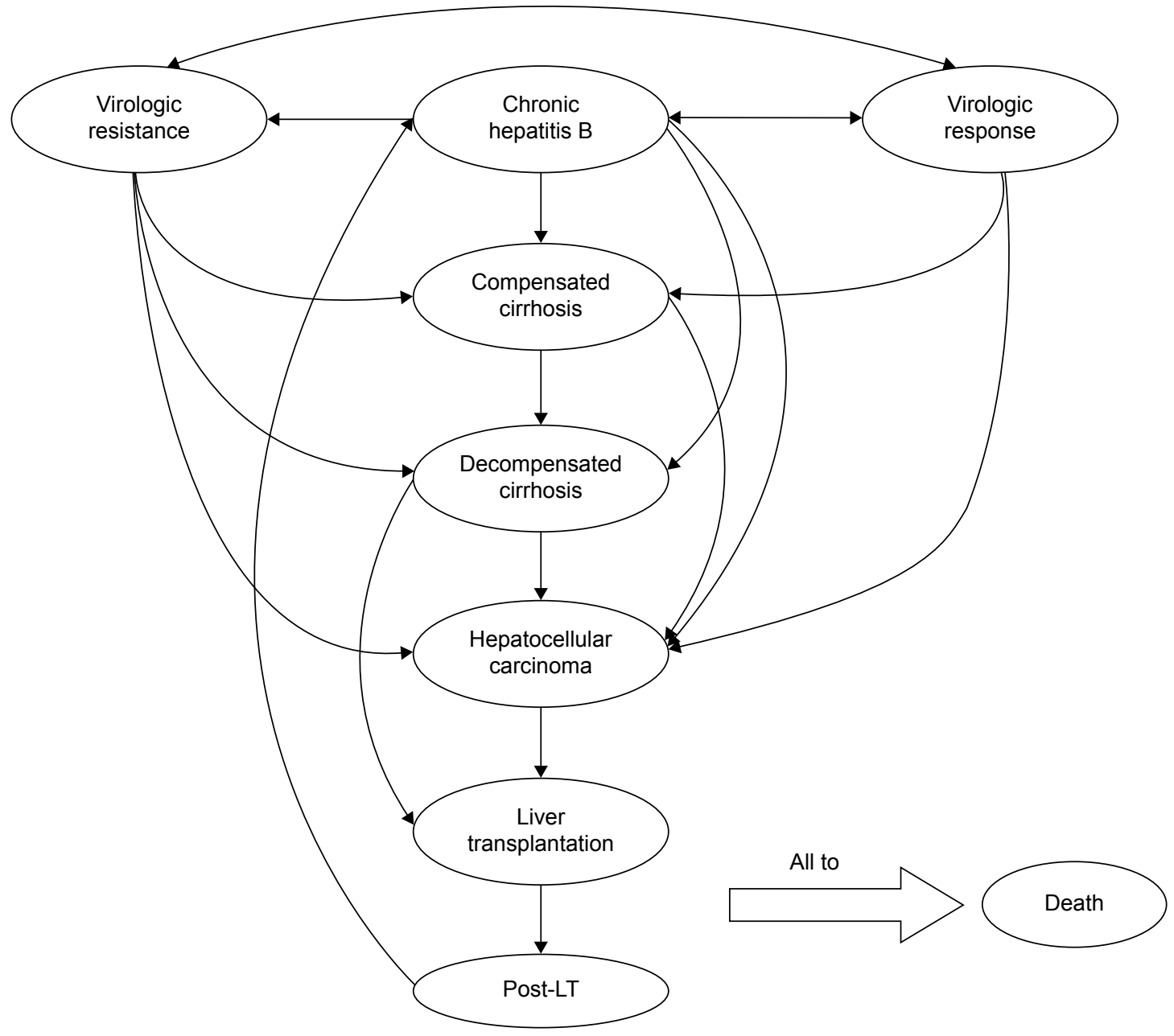

Figure I Diagram of CHB patient transition states in the Markov model. Abbreviations: post-LT, post-liver transplantation; CHB, chronic hepatitis B.

based on Chinese patients (Tables 1 and 2). Cumulative rates from original research were converted to an annual average rate based on the following formula:

$$
P=1-\left(1-P_{t}\right)^{1 / t},
$$

where $P$ is the annual transition rate for each cycle of the model, and $P_{t}$ is the cumulative rate for $t$ years. ${ }^{31}$ Metaanalysis was conducted to adjust for large variances in data extracted from the original literature.

\section{Cost and utility data}

Direct health-care costs related to CHB included costs arising from examinations, physician visits, laboratory testing, and disease complications (Table 3). ${ }^{32}$ Drug costs were taken from National Development and Reform Commission information. ${ }^{33}$ All costs were adjusted to 2014 prices using the China health-care consumer price index and then converted to 2014 values in US dollars (USD) using an exchange rate of 1 USD $=6.1429$ Chinese Yuan. ${ }^{26}$

Each disease state in the model was assigned a utility score between 0 (death) and 1 (perfect health) to quantify patient utilities for different disease states (Table 3). Utility estimates were derived from results for the Chinese population included in a multinational study conducted by Levy et al, ${ }^{34}$ which evaluated the utilities of CHB-related disease states using a standard gamble technique.

\section{Cost-effectiveness analysis}

Cumulative lifetime cost, LYS, and QALYs were used as outcome measures. A cost-effectiveness ratio (CER) was used to calculate the mean cost per one QALY for each treatment strategy. The therapy that generated the lowest lifetime cost was considered as the reference treatment. When a treatment had a greater efficacy and a greater cost in relation to the reference, an incremental cost-effectiveness 
Table I Annual transition rates of disease states used in the model (\%)

\begin{tabular}{|c|c|c|c|}
\hline Initial state & Entered state & Model input (range) & Reference numbers \\
\hline \multirow[t]{4}{*}{$\mathrm{CHB}$} & Compensated cirrhosis & $\mathrm{I} .0(0.8, \mathrm{I} .2)$ & Adjusted based on 43,44 \\
\hline & Decompensated cirrhosis & $0.5(0.3,0.7)$ & Adjusted based on 44,45 \\
\hline & Hepatocellular carcinoma & $0.4(0.3,0.5)$ & Adjusted based on 43,45 \\
\hline & Death & $0.9(0.8,1.0)$ & Adjusted based on 43,45 \\
\hline \multirow[t]{3}{*}{ Virologic response } & Compensated cirrhosis & $0.4(0.2,0.6)$ & 3 \\
\hline & Hepatocellular carcinoma & $0.2(0.1,0.3)$ & 3 \\
\hline & Death & Natural cause of death & 59 \\
\hline \multirow[t]{4}{*}{ Virologic resistance } & Compensated cirrhosis & $\mathrm{I} .0(0.8, \mathrm{I} .2)$ & Assumed equal to $\mathrm{CHB}$ \\
\hline & Decompensated cirrhosis & $0.5(0.3,0.7)$ & Assumed equal to $\mathrm{CHB}$ \\
\hline & Hepatocellular carcinoma & $0.4(0.3,0.6)$ & Assumed equal to $\mathrm{CHB}$ \\
\hline & Death & $0.9(0.8,1.0)$ & Assumed equal to $\mathrm{CHB}$ \\
\hline \multirow[t]{3}{*}{ Compensated cirrhosis } & Decompensated cirrhosis & $2.6(1.5,3.7)$ & Adjusted based on 45,46 \\
\hline & Hepatocellular carcinoma & I.8 $(0.8,2.8)$ & Adjusted based on 45,46 \\
\hline & Death & $2.5(1.5,3.5)$ & Adjusted based on 45,46 \\
\hline \multirow[t]{3}{*}{ Decompensated cirrhosis } & Hepatocellular carcinoma & $9.1(8.2,10.0)$ & 47 \\
\hline & Liver transplantation & $5.5(1.0,10.0)$ & 27 \\
\hline & Death & $10.4(9.4,11.4)$ & 48 \\
\hline \multirow[t]{2}{*}{ Hepatocellular carcinoma } & Liver transplantation & $5.5(1.0,10.0)$ & 27 \\
\hline & Death & $52.0(46.8,57.2)$ & 48 \\
\hline Liver transplantation & Death & $12.0(10.8,13.2)$ & 49 \\
\hline \multirow[t]{2}{*}{ Post-liver transplantation } & HBV relapse & $4.8(4.3,5.3)$ & 50 \\
\hline & Death & 8.I $(7.3,8.9)$ & 50 \\
\hline
\end{tabular}

Abbreviations: $\mathrm{CHB}$, chronic hepatitis B; HBV, hepatitis B virus.

ratio (ICER) was determined. An ICER was not calculated if a strategy had a greater cost but lower efficacy. In addition, according to the recommendation of the World Health Organization, the treatment strategy was acceptable for patients when the ICER was below the $3 \times$ Gross Domestic Product (GDP) ceiling ratio, ${ }^{32}$ and thus to identify the most cost-effective strategy, the willingness-to-pay (WTP) threshold was set as $\$ 20,466 /$ QALY gained (3× GDP per capita of China, 2014).

\section{Sensitivity analysis}

One-way sensitivity analysis was conducted to evaluate the uncertainty of each parameter, and the results were expressed as tornado charts. A probabilistic sensitivity analysis

Table 2 Treatment-related annual rates used in the model

\begin{tabular}{|c|c|c|c|c|}
\hline \multirow[t]{2}{*}{ Treatment } & \multicolumn{2}{|c|}{ Virologic response (\%) } & \multicolumn{2}{|c|}{ Resistance rate (\%) } \\
\hline & $\begin{array}{l}\text { Probability } \\
\text { (range) }\end{array}$ & $\begin{array}{l}\text { Reference } \\
\text { numbers }\end{array}$ & $\begin{array}{l}\text { Probability } \\
\text { (range) }\end{array}$ & $\begin{array}{l}\text { Reference } \\
\text { numbers }\end{array}$ \\
\hline \multicolumn{5}{|c|}{ HBeAg-positive } \\
\hline LAM & $35(27,43)$ & 9,51 & $17.0(12.1,21.9)$ & 9,51 \\
\hline ADV & $23(14,32)$ & 8,52 & $3.1(1.3,4.9)$ & 8 \\
\hline TBV & $64(61,67)$ & 9,17 & $8.1(7.5,8.7)$ & 9,10 \\
\hline ETV & $69(62,76)$ & $17,51,52$ & $0.9(0.6,1.2)$ & $5 I, 53$ \\
\hline TDF & $75(73,77)$ & $17,54,55$ & $0.5(0.1,0.9)$ & 54,56 \\
\hline LAM + ADV & $77(66,88)$ & $18-20$ & $0.8(0.1,1.5)$ & $18,22,23$ \\
\hline \multicolumn{5}{|c|}{ HBeAg-negative } \\
\hline LAM & $75(73,77)$ & 9,60 & $17.0(\mid 2.1,21.9)$ & 9,51 \\
\hline ADV & $61(59,63)$ & 52 & $3.1(1.3,4.9)$ & 8 \\
\hline TBV & $85(80,90)$ & 9 & $8.1(7.5,8.7)$ & 9,10 \\
\hline ETV & $90(86,94)$ & $17,51,60$ & $0.8(0.6, \mathrm{I} .2)$ & $5 \mathrm{I}, 53$ \\
\hline TDF & $94(92,96)$ & $17,54,55$ & $0.5(0.1,0.9)$ & 54,56 \\
\hline LAM + ADV & $91(87,95)$ & 18,24 & $0.8(0.1,1.5)$ & $18,22,23$ \\
\hline \multicolumn{5}{|c|}{ Rescue strategies } \\
\hline LAM + ADV & $63(52,74)$ & 15 & $6.9(6.2,7.6)$ & 15 \\
\hline ETV + ADV & $73(65,81)$ & 15 & 0.0 & 15 \\
\hline
\end{tabular}

Abbreviations: $\mathrm{HBeAg}$, hepatitis B e antigen; LAM, lamivudine; ADV, adefovir; TBV, telbivudine; ETV, entecavir; TDF, tenofovir. 
Table 3 Annual costs (US dollars, 2014 values) and disease-state utilities

\begin{tabular}{|c|c|c|}
\hline $\begin{array}{l}\text { Average disease costs } \\
\text { (per patient/year) }\end{array}$ & $\begin{array}{l}\text { Base case } \\
\text { (range) }\end{array}$ & $\begin{array}{l}\text { Reference } \\
\text { numbers }\end{array}$ \\
\hline \multicolumn{3}{|l|}{ Drug costs } \\
\hline LAM & $913(822,1,004)$ & 33 \\
\hline ADV & $1,059(953,1,165)$ & 33 \\
\hline TBV & $1,314(1,183,1,445)$ & 33 \\
\hline ETV & $2,044(1,840,2,248)$ & 33 \\
\hline TDF & $3,176(2,858,3,494)$ & Local pharmacy \\
\hline \multicolumn{3}{|l|}{ Disease-state costs } \\
\hline $\mathrm{CHB}$ & $\mathrm{I}, 876(1,688,2,064)$ & 57 \\
\hline Virologic response & $1,876(1,688,2,064)$ & $\begin{array}{l}\text { Assumed equal } \\
\text { to } \mathrm{CHB}\end{array}$ \\
\hline Virologic resistance & $\mathrm{I}, 876(\mathrm{I}, 688,2064)$ & $\begin{array}{l}\text { Assumed equal } \\
\text { to } \mathrm{CHB}\end{array}$ \\
\hline Compensated cirrhosis & $2,853(2,568,3,138)$ & 57 \\
\hline Decompensated cirrhosis & $5,274(4,747,5,80 I)$ & 57 \\
\hline Hepatocellular carcinoma & $7,930(7,137,8,723)$ & 57 \\
\hline Liver transplantation & $62,00 \mathrm{I}(55,80 \mathrm{I}, 68,20 \mathrm{I})$ & 58 \\
\hline Post-liver transplantation & $9,391(8,452,10,330)$ & 58 \\
\hline \multicolumn{3}{|c|}{ Disease-state utilities (QALYs) } \\
\hline $\mathrm{CHB}$ & $0.52(0.47,0.57)$ & 34 \\
\hline Virologic response & $0.7 \mathrm{I}(0.64,0.78)$ & 34 \\
\hline Virologic resistance & $0.52(0.47,0.57)$ & $\begin{array}{l}\text { Assumed equal } \\
\text { to } \mathrm{CHB}\end{array}$ \\
\hline Compensated cirrhosis & $0.57(0.5 \mathrm{I}, 0.63)$ & 34 \\
\hline Decompensated cirrhosis & $0.26(0.23,0.29)$ & 34 \\
\hline Hepatocellular carcinoma & $0.3 \mathrm{I}(0.28,0.34)$ & 34 \\
\hline Liver transplantation & $0.4 \mathrm{I}(0.37,0.45)$ & 34 \\
\hline Post-liver transplantation & $0.55(0.49,0.6 \mathrm{I})$ & 34 \\
\hline
\end{tabular}

Notes: All drug costs and direct disease-state costs are expressed in 2014 US dollars (\$, USD) per patient/year.

Abbreviations: LAM, lamivudine; ADV, adefovir; TBV, telbivudine; ETV, entecavir; TDF, tenofovir; CHB, chronic hepatitis B; QALYs, quality-adjusted life years.
(PSA) based on a second-order Monte Carlo simulation of 1,000 patients was also performed, ${ }^{35}$ and cost-effectiveness acceptability curves or scatter plots of pairwise coupling were generated. Appropriate distributions were correspondingly assigned to the input parameters in the model, wherein $\beta$ distributions were assumed for probability and utility values, and $\gamma$ distributions were used for cost variables.

\section{Results}

\section{Base-case analysis}

The model simulated the lifetime of CHB patients and calculated the cumulative costs, LYS, QALYs, CER, and ICER (Table 4). Health outcomes (such as 10-year cumulative incidence of compensated cirrhosis, decompensated cirrhosis, and HCC of six drug therapy options) are shown in Figure 2. In the $\mathrm{HBe} A g-$ positive cohort, LAM plus ADV combination therapy was the most efficacious, achieving 15.90 LYS and 10.98 QALYs. In the HBeAg-negative cohort, TDF generated the highest number of LYS and QALYs, with 15.87 and 10.93 years, respectively. In the $\mathrm{HBeAg}$-positive cohort, the 10-year cumulative incidences of compensated cirrhosis, decompensated cirrhosis, HCC, and death for LAM plus ADV combination therapy were $4.58 \%, 1.17 \%, 2.82 \%$, and $5.50 \%$, respectively. Meanwhile, the incidences of advanced liver diseases for TDF were $4.46 \%, 1.04 \%, 2.73 \%$, and $5.18 \%$, respectively, in the HBeAg-negative cohort.

In both patient groups, the least expensive strategy over a lifetime was ETV, which served as the reference therapy.

Table 4 Base-case cost and effectiveness of treatment strategies

\begin{tabular}{|c|c|c|c|c|c|c|}
\hline Drug & ETV $^{\mathbf{a}}$ & LAM & ADV & TBV & TDF & LAM + ADV \\
\hline \multicolumn{7}{|l|}{ HBeAg-positive patients } \\
\hline Cost $(\times \$ 1,000)$ & 72.15 & 83.48 & 81.24 & 76.63 & 82.64 & 74.45 \\
\hline QALYs & 10.88 & 10.55 & 10.59 & 10.68 & 10.93 & 10.98 \\
\hline LYS & 15.84 & 15.64 & 15.66 & 15.73 & 15.87 & 15.90 \\
\hline Incremental cost $(\times \$ 1,000)$ & - & -11.33 & -9.09 & -4.48 & -10.49 & -2.30 \\
\hline Incremental LYS & - & 0.20 & 0.18 & 0.11 & -0.03 & -0.06 \\
\hline Incremental QALYs & - & 0.33 & 0.29 & 0.20 & -0.05 & -0.10 \\
\hline CER $(\times \$ 1,000 / Q A L Y s)$ & 6.63 & 7.91 & 7.67 & 7.18 & 7.56 & 6.78 \\
\hline ICER $(\times \$ 1,000 / Q A L Y s)$ & - & Dominated & Dominated & Dominated & 209.80 & 23.00 \\
\hline \multicolumn{7}{|l|}{ HBeAg-negative patients } \\
\hline Cost $(\times \$ 1,000)$ & 67.15 & 78.30 & 69.92 & 72.82 & 80.99 & 69.84 \\
\hline QALYs & 11.00 & 10.62 & 10.76 & 10.74 & 11.05 & 11.02 \\
\hline LYS & 15.92 & 15.70 & 15.78 & 15.77 & 15.94 & 15.93 \\
\hline Incremental cost $(\times \$ 1,000)$ & - & -11.15 & -2.77 & -5.67 & -13.84 & 2.69 \\
\hline Incremental LYS & - & 0.22 & 0.14 & 0.15 & -0.02 & -0.01 \\
\hline Incremental QALYs & - & 0.38 & 0.24 & 0.26 & -0.05 & -0.02 \\
\hline CER $(\times \$ 1,000 / Q A L Y s)$ & 6.10 & 7.37 & 6.50 & 6.78 & 7.33 & 6.34 \\
\hline ICER ( $\times \$ 1,000 / Q A L Y s)$ & - & Dominated & Dominated & Dominated & 276.80 & 134.50 \\
\hline
\end{tabular}

Notes: aThe therapy used as a reference treatment. All costs are expressed in 2014 US dollars (\$). Dominated: The therapy has higher cost and lower efficacy in comparison with the reference treatment. ICER is calculated by using the formula ICER = Incremental cost/Incremental QALYs. “-” ETV was the baseline comparator.

Abbreviations: ETV, entecavir; LAM, lamivudine; ADV, adefovir; TBV, telbivudine; TDF, tenofovir; HBeAg, hepatitis B e antigen; QALYs, quality-adjusted life years; LYS, life years saved; ICER, incremental cost-effectiveness rate. 
Compared with other treatment options, ETV also achieved an excellent CER, indicating that ETV had the lowest cost per one QALY (HBeAg-positive: \$6,630/QALY, HBeAg-negative: \$6,100/QALY). LAM, ADV, and TBV were more cost-effective, but less efficacious than ETV. With respect to ETV, TDF had the highest lifetime cost, and the ICER of TDF (HBeAg-positive: \$209,800/QALY gained; HBeAg-negative: \$276,800/QALY gained) was far higher than the WTP threshold of \$20,466/QALY gained. The LAM plus ADV combination therapy achieved more LYS and QALY than ETV, but was also more expensive. The ICER of LAM plus ADV combination therapy compared with ETV was \$23,000/QALY gained for HBeAg-positive and \$134,500/QALY gained for HBeAgnegative cohorts, which was also higher than the WTP threshold (Figure 3).

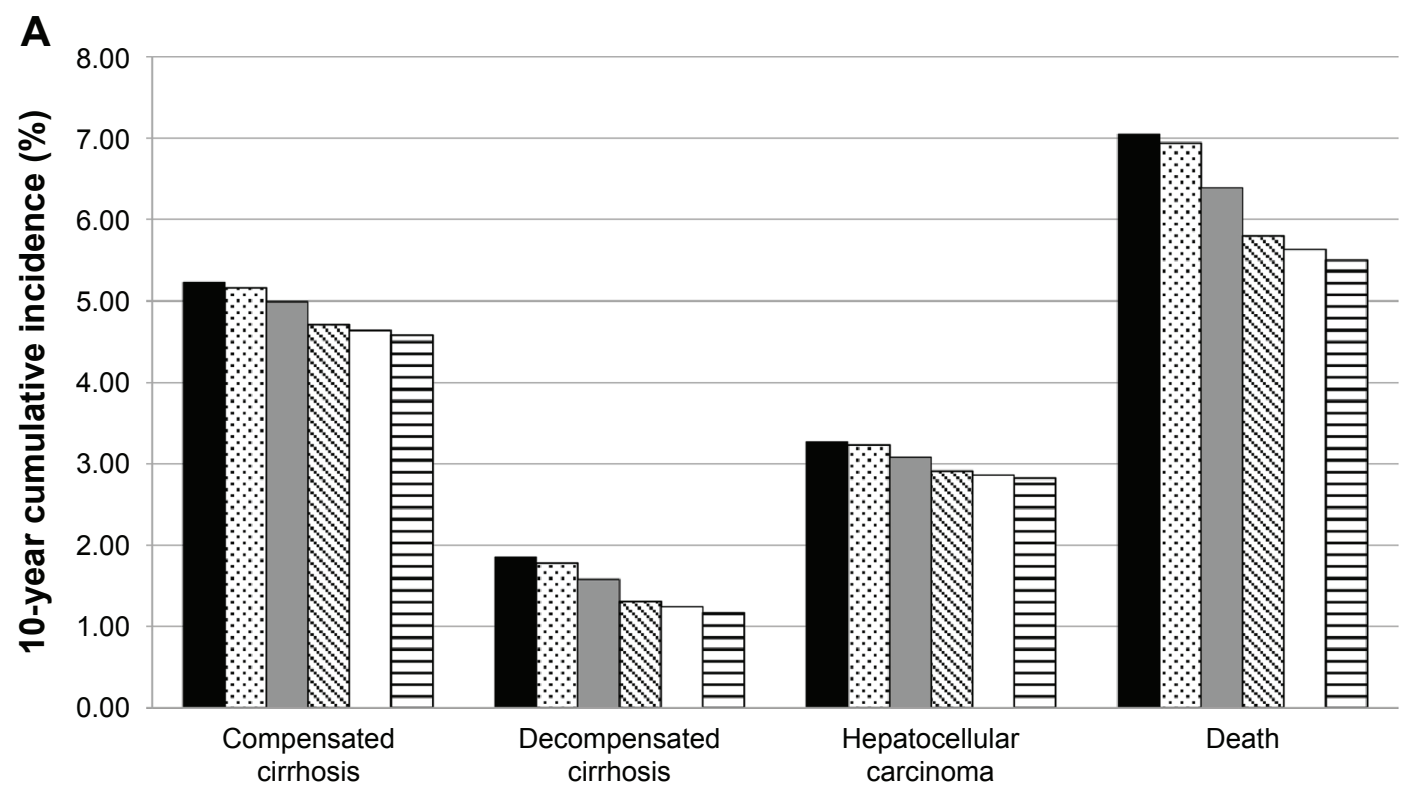

Disease complications of HBeAg-positive CHB patients

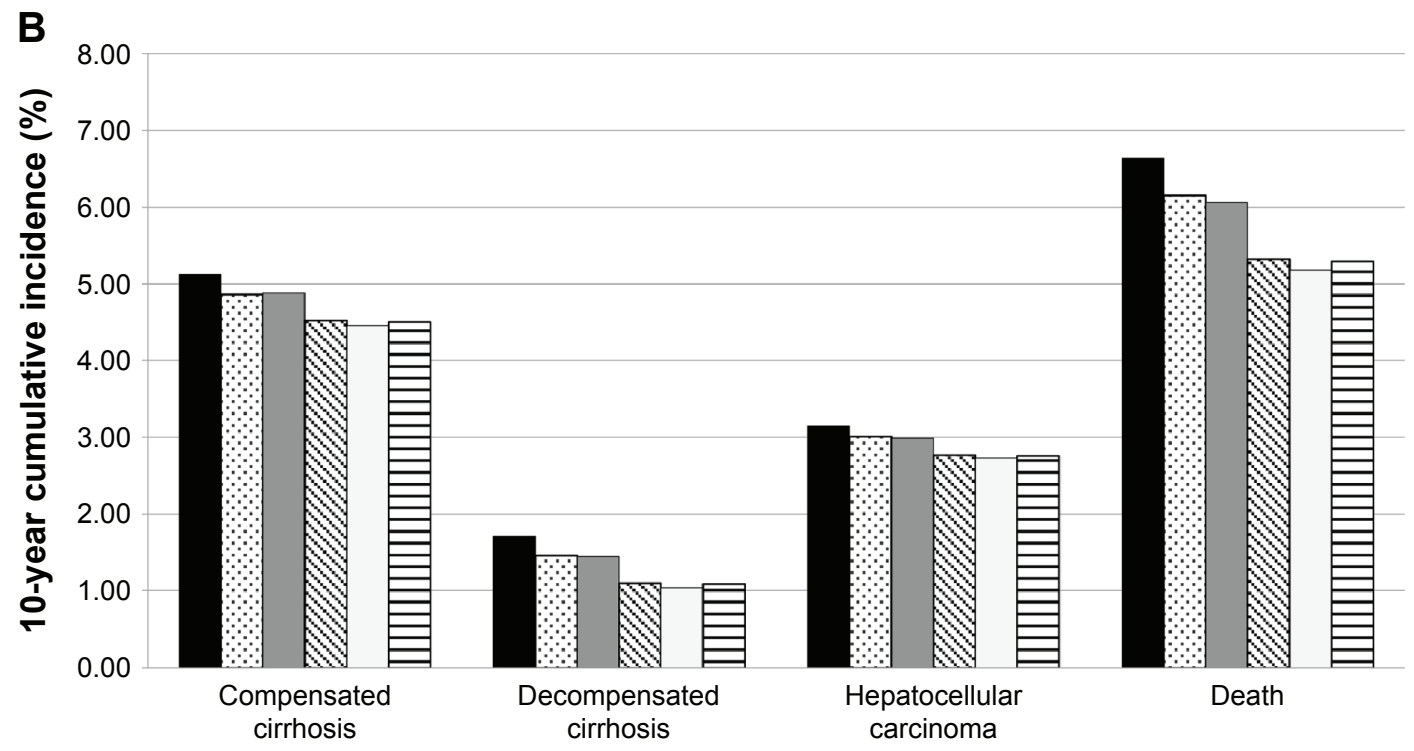

Disease complications of HBeAg-negative CHB patients

$\square$ LAM EADV $\square$ TBV SETV $\square$ TDF ELAM + ADV

Figure 2 Ten-year cumulative incidence of advanced liver diseases for $\mathrm{HBeAg}$-positive $(\mathbf{A})$ and -negative (B) CHB patients after different therapy strategies. Abbreviations: LAM, lamivudine; ADV, adefovir; TBV, telbivudine; ETV, entecavir; TDF, tenofovir; $\mathrm{HBeAg}$, hepatitis $B$ e antigen; CHB, chronic hepatitis B. 
A

\begin{tabular}{|c|c|c|c|c|}
\hline $\boldsymbol{\Delta}$ ADV & - ETV & - LAM & $\boldsymbol{\nabla}$ LAM + ADV & $\star$ TBV \\
\hline
\end{tabular}

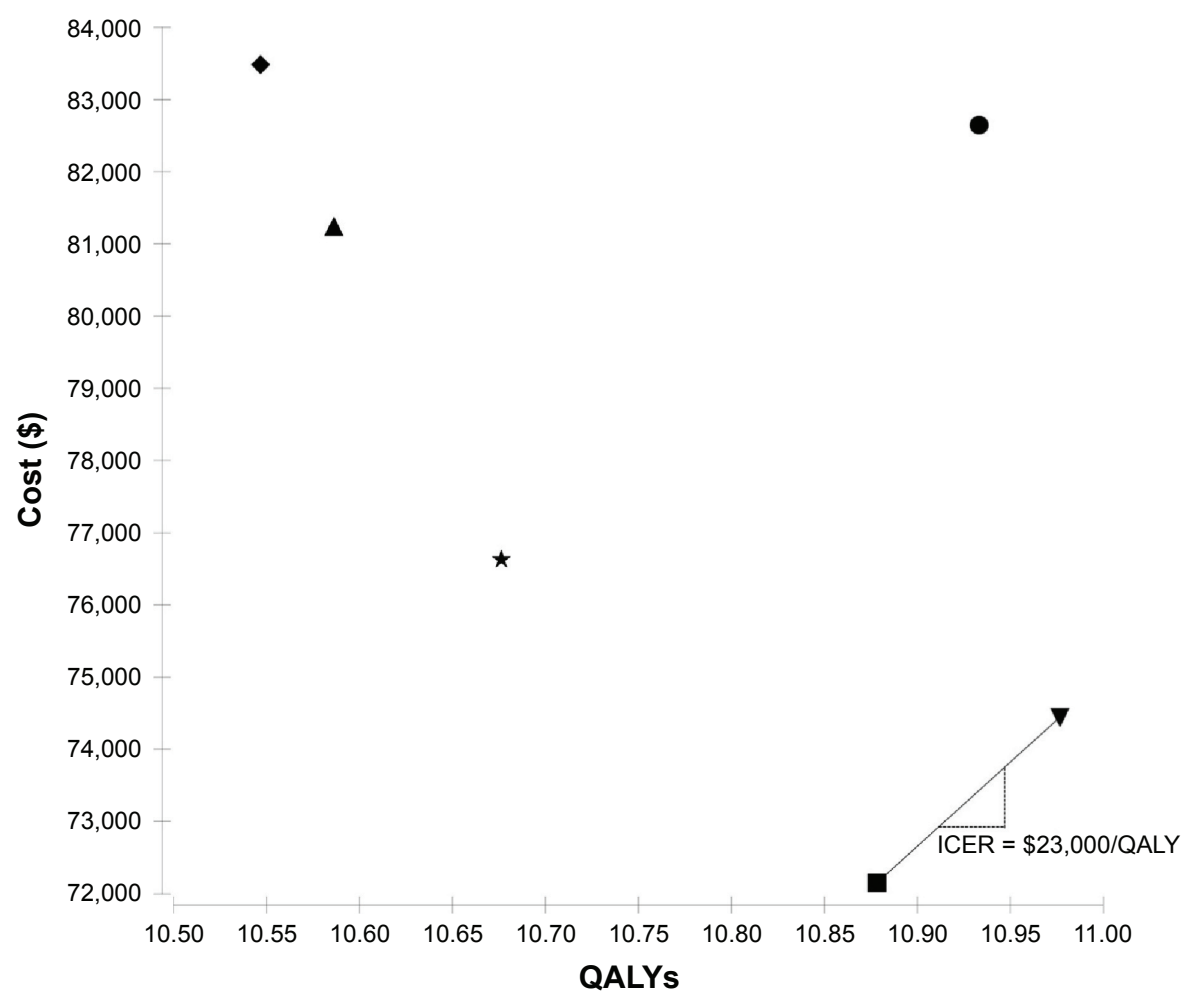

B

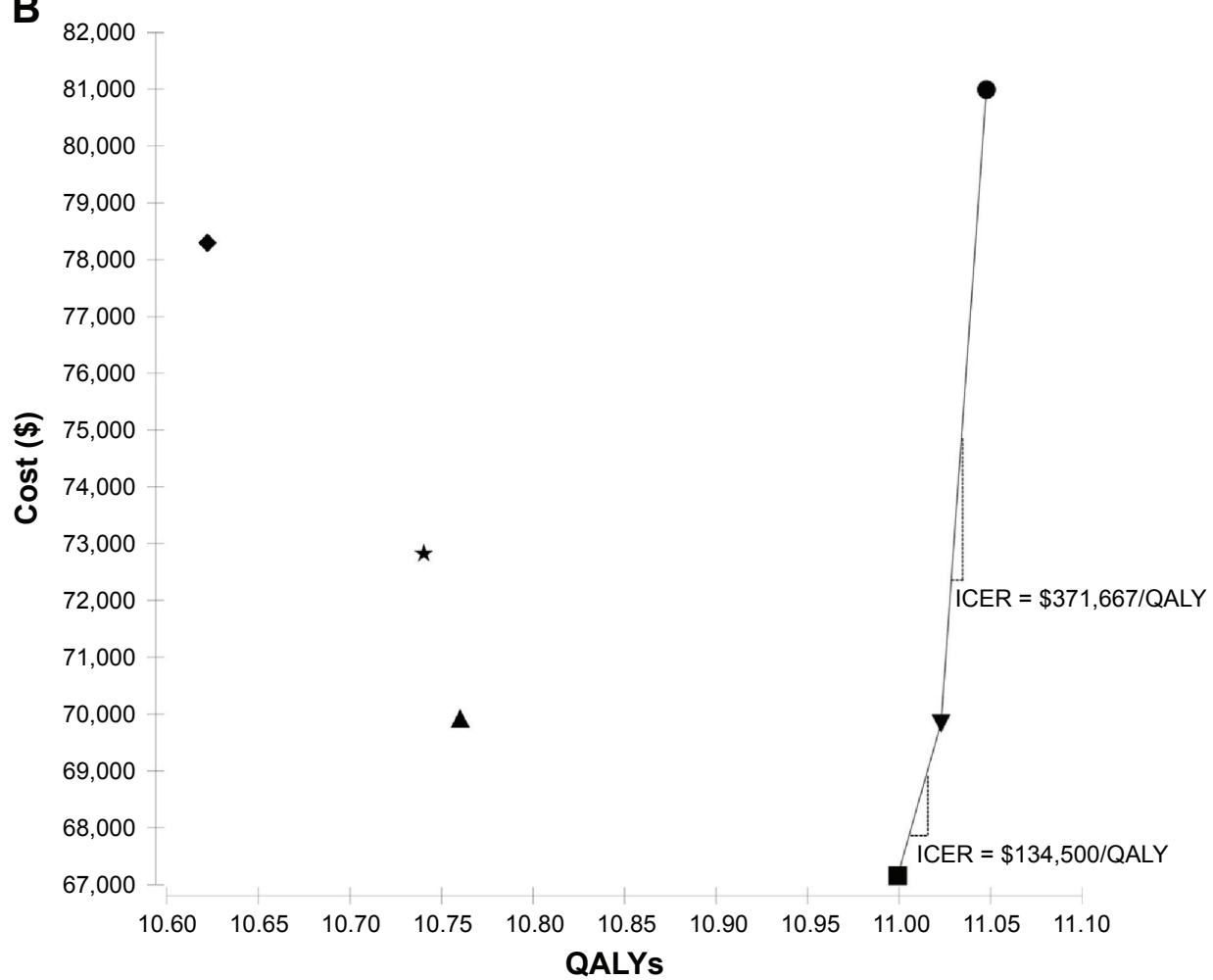

Figure 3 Cost-effectiveness of different treatment strategies for $\mathrm{HBeAg}$-positive $(\mathbf{A})$ and -negative (B) chronic hepatitis $B$ patients.

Notes: The $x$-axis represents the life-time QALYs for each treatment, and the $y$-axis indicates the life-time costs (US dollars). The straight lines represent the costeffectiveness frontier, which joins the treatments that are not dominated by any other treatment. The slope of this line at any point represents the ICER for the comparison between the treatments at either end of the line.

Abbreviations: LAM, lamivudine; ADV, adefovir; TBV, telbivudine; ETV, entecavir; TDF, tenofovir; QALYs, quality-adjusted life years; HBeAg, hepatitis B e antigen; ICER, incremental cost-effectiveness ratio. 


\section{Alternative scenario analysis}

Table 5 shows the results of alternative rescue treatment strategies (direct use of ETV plus ADV combination rescue therapy). In contrast to base-case analysis, the lowest lifetime cost and best CER (HBeAg-positive: \$6,780/QALY; HBeAg-negative: \$6,340/QALY) were obtained with LAM plus ADV combination treatment, and thus this combination was used as the reference therapy. As LAM, ADV, and TBV had higher cost and lower efficacy than LAM plus ADV combination therapy, they were directly dominated by the combination therapy in both cohorts. ETV and TDF were also dominated by LAM plus ADV combination therapy, except in the HBeAg-negative cohort. However, the ICER of ETV and TDF versus LAM plus ADV combination treatment was far higher than the WTP threshold of \$20,466/QALY gained in the HBeAg-negative group.

\section{One-way sensitivity analysis}

One-way sensitivity analysis for ETV was conducted by varying all model parameters based on their range of values. The ten most influential parameters are presented as a tornado diagram (Figure 4). In both cohorts, the most influential parameter was found to be the utility of virologic response. However, none of the variations would change the finding that ETV was the most cost-effective treatment, except for the virologic response and resistance rate of LAM plus ADV combination treatment. By using the threshold analysis, LAM plus ADV combination therapy would become the optimal therapy when the response rate was above $78 \%$ or the resistance rate was below $0.8 \%$ in the $\mathrm{HBeAg}$-positive cohort, and for the $\mathrm{HBeAg-negative} \mathrm{cohort} \mathrm{response} \mathrm{and} \mathrm{resistance} \mathrm{rates}$ had to be above $93 \%$ and below $0.4 \%$, respectively.

\section{Probabilistic sensitivity analysis}

The PSA showed that at the WTP threshold of $\$ 20,466 /$ QALY gained, ETV was the most cost-effective treatment in $46.3 \%$ and $55.7 \%$ of the simulations for HBeAg-positive and HBeAg-negative groups, respectively (Figure 5). LAM plus ADV combination therapy would be the preferable option when the threshold was beyond \$24,000/QALY gained for the HBeAg-positive cohort, or $\$ 83,000 /$ QALY gained for the HBeAg-negative cohort.

Scatter plots indicated that in the HBeAg-positive cohort, ETV dominated LAM, ADV, TBV, TDF, and LAM and ADV combination therapy in 100.0\%, 99.8\%, 84.0\%, 97.2\%, and $54.0 \%$ simulations, respectively, that were under the \$20,466/QALY gained threshold (Figure 6). Among HBeAgnegative patients, the percentages of simulations where ETV dominated were $100.0 \%, 93.6 \%, 95.0 \%, 99.4 \%$, and $60.1 \%$, respectively (Figure 6).

\section{Discussion}

Hepatitis B is a major global public health concern, especially in China. Persistent HBV infection has been a critical

Table 5 Alternative cost and effectiveness of five treatment strategies

\begin{tabular}{|c|c|c|c|c|c|c|}
\hline Drug & LAM + ADV $\mathbf{a}$ & LAM & ADV & TBV & ETV & TDF \\
\hline \multicolumn{7}{|l|}{ HBeAg-positive patients } \\
\hline Cost $(\times \$ 1,000)$ & 74.45 & 99.88 & 96.42 & 89.47 & 78.84 & 87.68 \\
\hline QALYs & 10.98 & 10.70 & 10.73 & 10.79 & 10.94 & 10.98 \\
\hline LYS & 15.90 & 15.72 & 15.74 & 15.79 & 15.87 & 15.90 \\
\hline Incremental cost $(\times \$ 1,000)$ & - & -25.43 & -21.97 & -15.02 & -4.39 & -13.23 \\
\hline Incremental LYS & - & 0.18 & 0.16 & 0.11 & 0.03 & $<0.01$ \\
\hline Incremental QALYs & - & 0.28 & 0.25 & 0.19 & 0.04 & $<0.01$ \\
\hline CER $(\times \$ 1,000 / Q A L Y s)$ & 6.78 & 9.33 & 8.99 & 8.29 & 7.21 & 7.99 \\
\hline ICER (×\$I,000/QALYs) & - & Dominated & Dominated & Dominated & Dominated & Dominated \\
\hline \multicolumn{7}{|l|}{ HBeAg-negative patients } \\
\hline Cost $(\times \$ 1,000)$ & 69.84 & 92.69 & 80.21 & 83.93 & 70.36 & 82.72 \\
\hline QALYs & 11.02 & 10.75 & 10.85 & 10.84 & 11.03 & 11.06 \\
\hline LYS & 15.93 & 15.76 & 15.82 & $15.8 \mid$ & 15.93 & 15.95 \\
\hline Incremental cost $(\times \$ 1,000)$ & - & -22.85 & -10.37 & -14.09 & -0.52 & -12.88 \\
\hline Incremental LYS & - & 0.17 & 0.11 & 0.12 & $<0.01$ & -0.02 \\
\hline Incremental QALYs & - & 0.27 & 0.17 & 0.18 & -0.01 & -0.04 \\
\hline CER $(\times \$ 1,000 / Q A L Y s)$ & 6.34 & 8.62 & 7.39 & 7.74 & 6.38 & 7.48 \\
\hline ICER $(\times \$ 1,000 / Q A L Y s)$ & - & Dominated & Dominated & Dominated & 52.00 & 322.00 \\
\hline
\end{tabular}

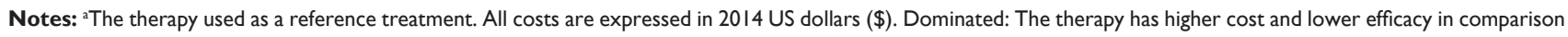
with the reference treatment. ICER is calculated by using the formula ICER = Incremental cost/Incremental QALYs. "-” LAM+ADV is the baseline comparator.

Abbreviations: LAM, lamivudine; ADV, adefovir; TBV, telbivudine; ETV, entecavir; TDF, tenofovir; HBeAg, hepatitis B e antigen; QALYs, quality-adjusted life years; LYS, life years saved; ICER, incremental cost-effectiveness rate. 
A

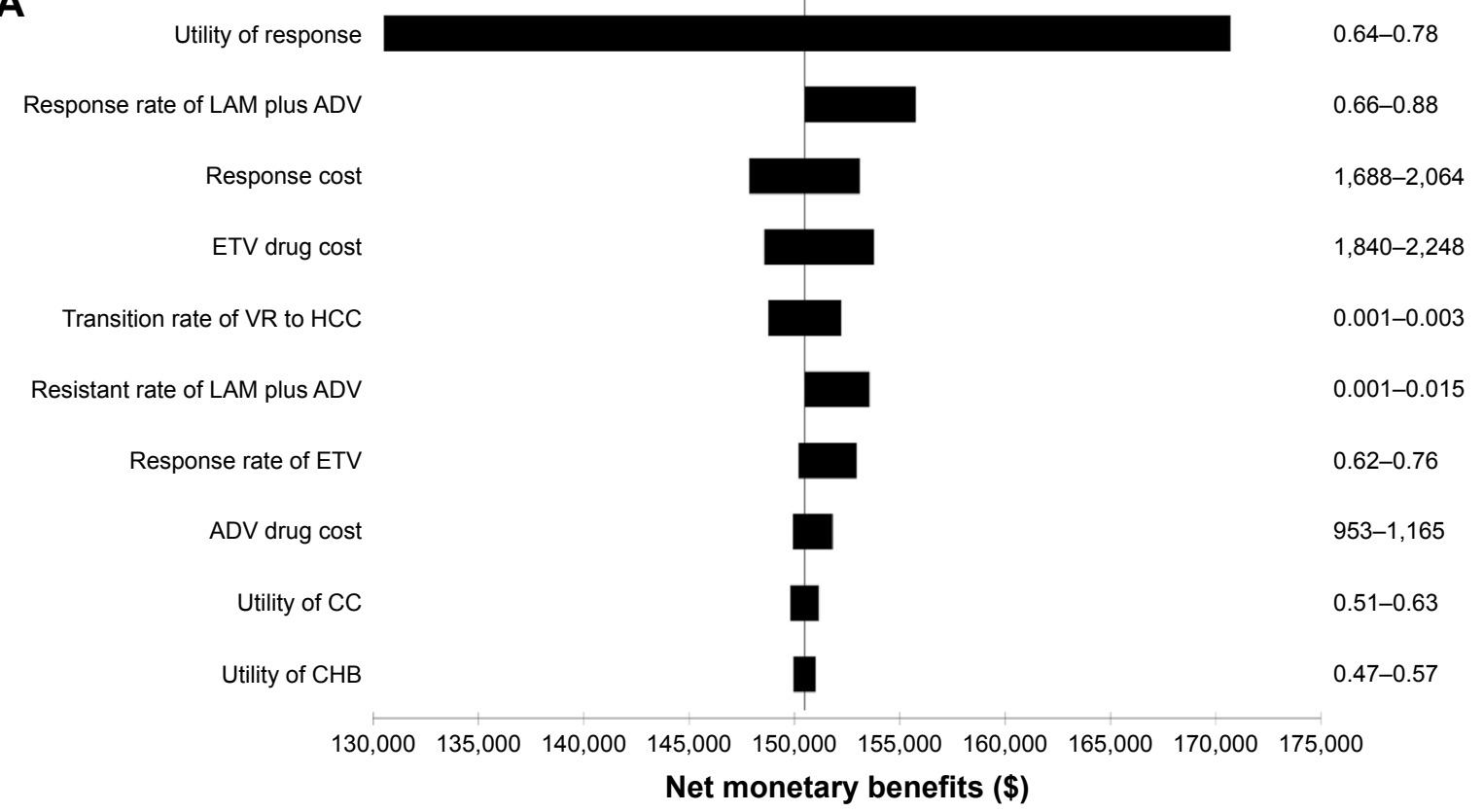

B

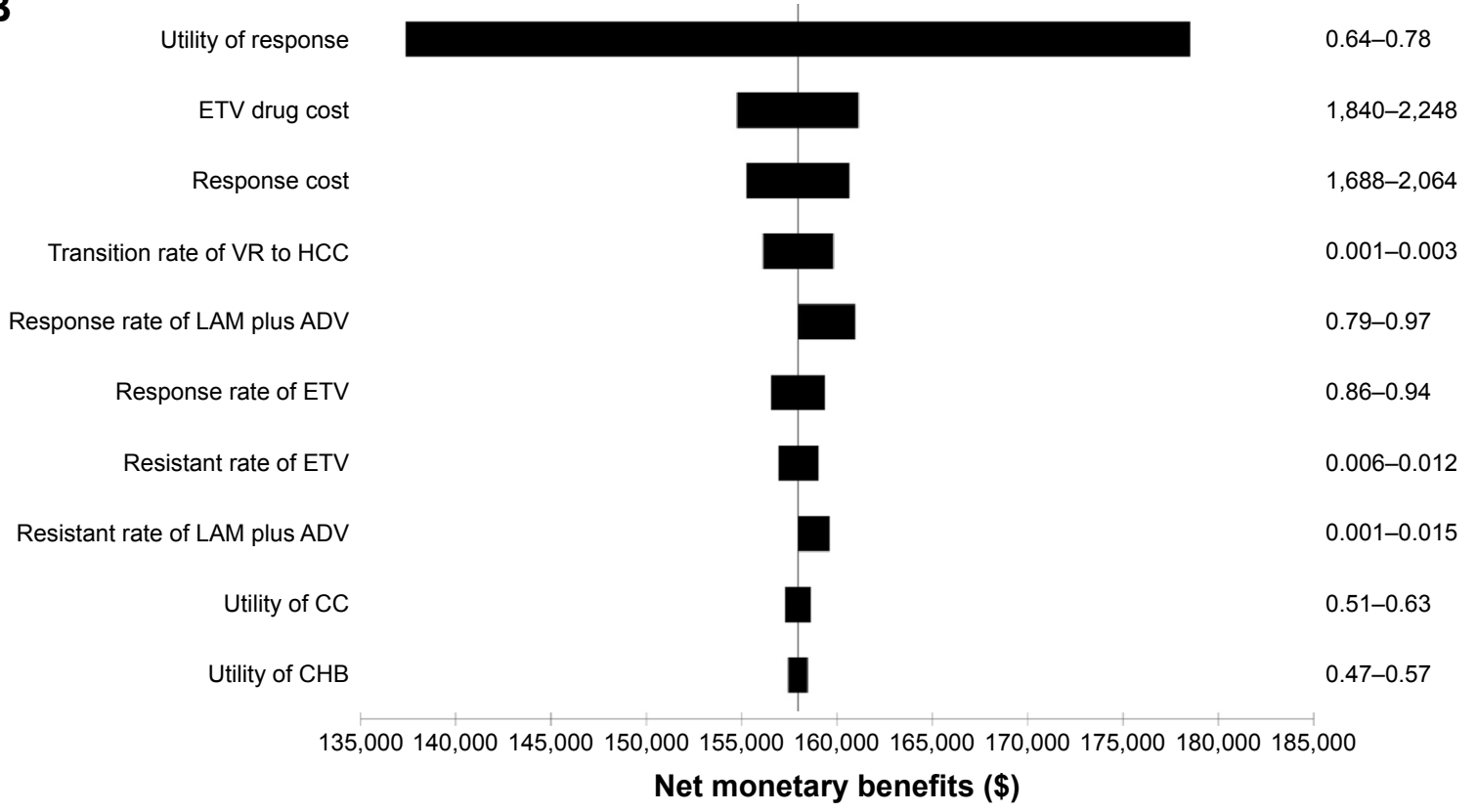

Figure 4 Results of one-way sensitivity analysis for HBeAg-positive (A) and -negative (B) CHB patients at a threshold of $\$ 20,466 / \mathrm{QALY}$ gained.

Note: The vertical dotted line represents the base-case results where ETV was the most cost-effective strategy.

Abbreviations: LAM, lamivudine; ADV, adefovir; ETV, entecavir; VR, virologic response; HCC, hepatocellular carcinoma; CC, compensated cirrhosis; CHB, chronic hepatitis B; HBeAg, hepatitis B e antigen; QALYs, quality-adjusted life years.

risk factor in CHB patients who, in the absence of timely and effective therapy, ultimately progress to cirrhosis and HCC. ${ }^{3,36}$ CHB-related complications can lead to significant mortality and substantial economic consequences. ${ }^{37}$ For $\mathrm{CHB}$ patients in China, LAM remains a promising option because its price is the lowest of the five currently available nucleos $(\mathrm{t})$ ide analogs. However, due to the high resistance rate of LAM, patients will eventually have to switch or combine with other antiviral drugs for continuous therapy, which ultimately results in higher costs for long-term treatment. ${ }^{9}$ Recently, ADV was found to have no cross-resistance with LAM, TBV, and ETV, and thus this drug is used as a basic agent for combination therapy. ${ }^{11,38,39}$ In 2011, LAM plus ADV combination therapy was recommended for initial treatment of CHB patients. ${ }^{25}$ Nonetheless, this recommendation does not take into account cost-effectiveness as a factor for selecting 

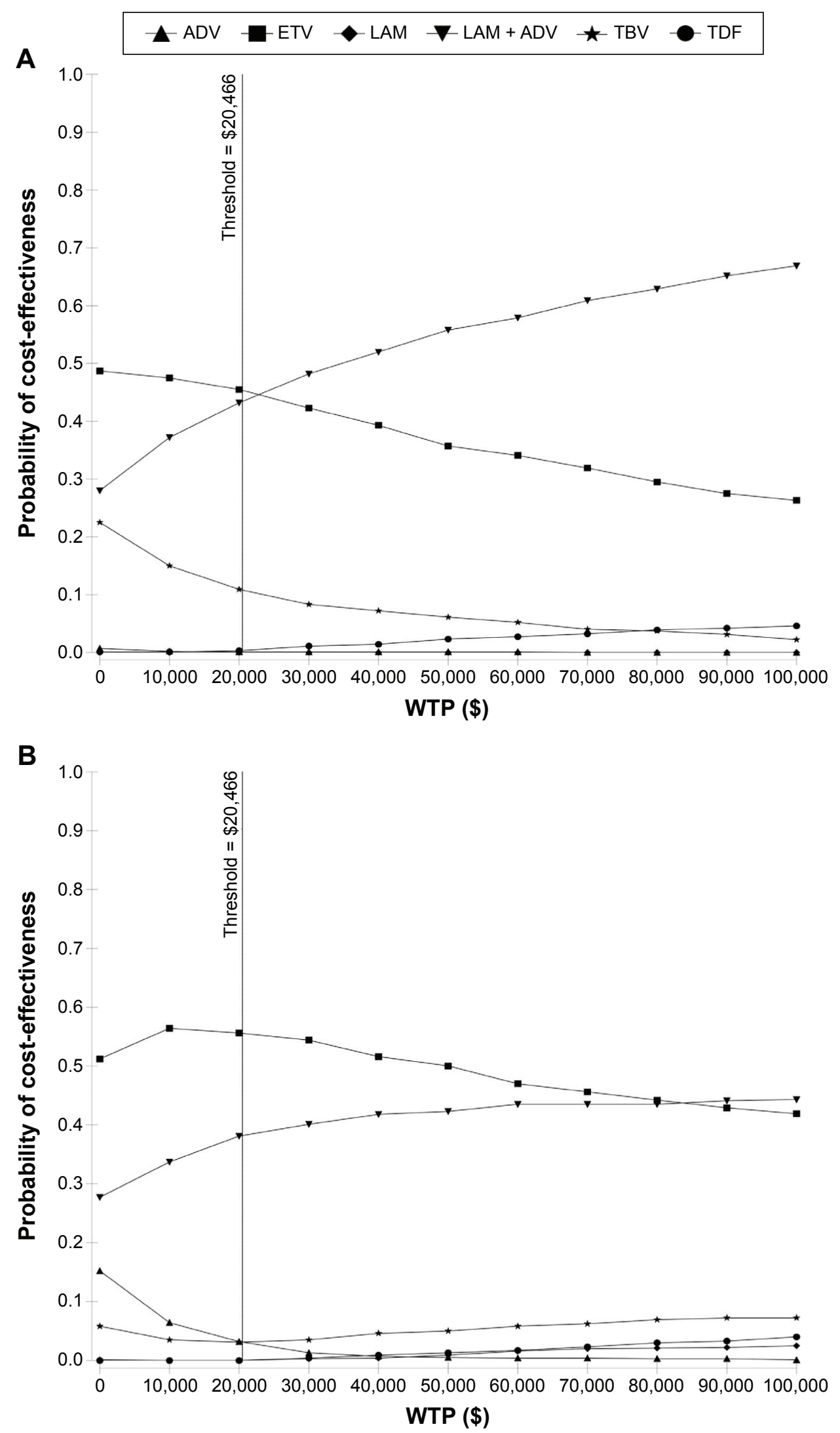

Figure 5 Cost-effectiveness acceptability curves of different strategies for HBeAg-positive (A) and -negative (B) chronic hepatitis B patients.

Notes: The $y$-axis indicates the probability that the therapy is a cost-effective strategy. The $x$-axis represents the WTP threshold to pay one additional QALY.

Abbreviations: ADV, adefovir; ETV, entecavir; LAM, lamivudine; TBV, telbivudine; TDF, tenofovir; HBeAg, hepatitis B e antigen; WTP, willingness-to-pay; QALY, qualityadjusted life year. 
+ HBeAg-positive $\bullet$ HBeAg-negative

A

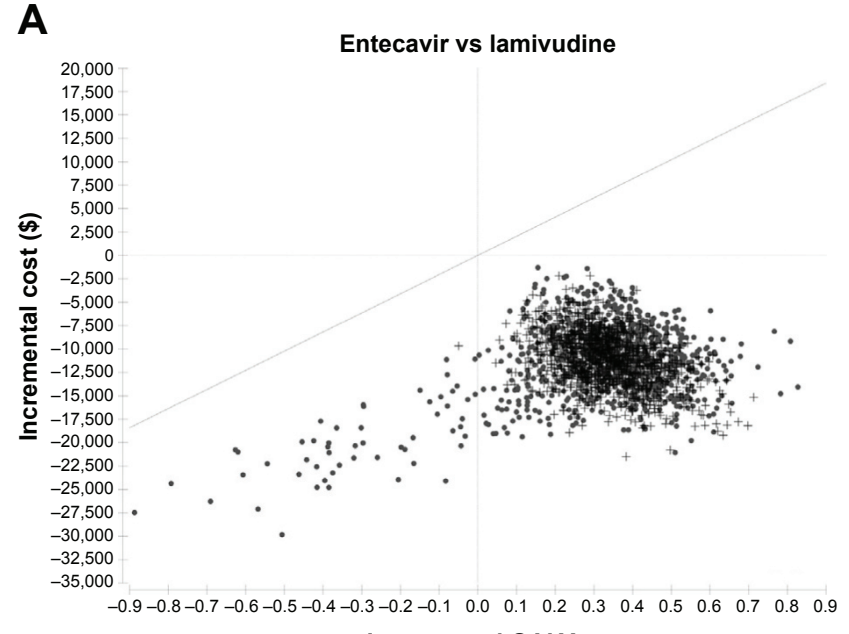

Incremental QALYs

\section{C}

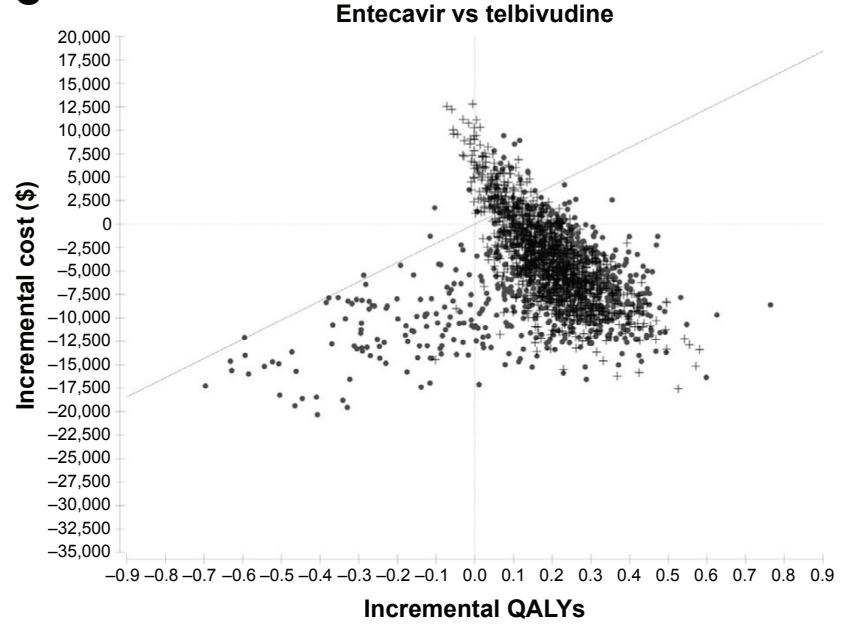

\section{B}

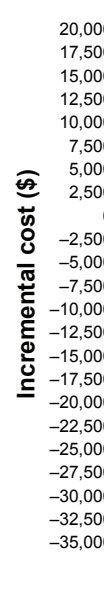

Entecavir vs adefovir

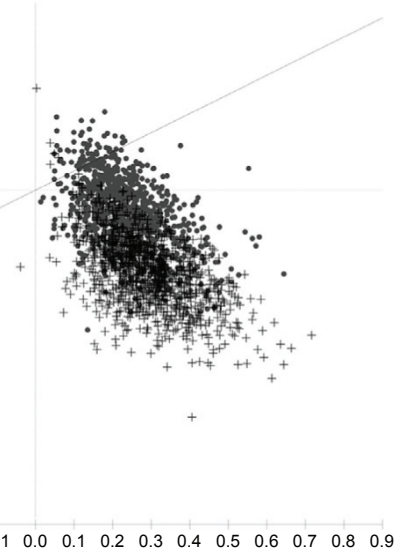

Incremental QALYs

D

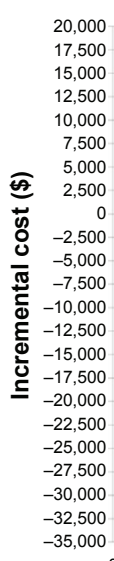

Entecavir vs tenofovir

, 000

7,500

12,500

500

5,000
2,500

0
$-2,500$

$-5,000$

$-7,500$
$-10,000$
$-12,500$

$-10,000$

$-15,000$

$-20,000$

$-22,500$

$-27,500$

$-32,500$

$-0.9-0.8-0.7-0.6-0.5-0.4-0.3-0.2-0.1 \quad 0.0 \quad 0.1 \quad 0.2 \quad 0.3 \quad 0.4 \quad 0.5 \quad 0.6 \quad 0.7 \quad 0.8 \quad 0.9$ Incremental QALYs

E

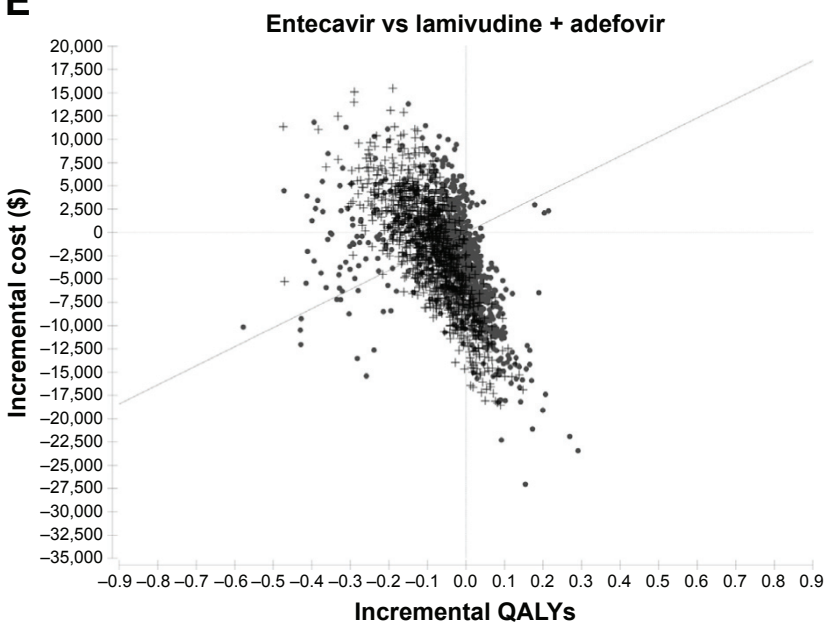

Figure 6 Probabilistic results for incremental cost-effectiveness comparisons between treatment with entecavir and (A) lamivudine monotherapy, (B) adefovir monotherapy, (C) telbivudine monotherapy, (D) tenofovir monotherapy, and (E) lamivudine plus adefovir combination therapy for a simulation involving I,000 patients.

Notes: The $y$ - and $x$-axes represent the incremental costs and incremental QALYs gained, respectively. Dots below the ICER threshold reflect simulations in which cost per QALYs gained with entecavir are below the Chinese threshold of \$20,466/QALY gained.

Abbreviations: QALYs, quality-adjusted life years; ICER, incremental cost-effectiveness ratio. 
suitable therapies. As such, a current economic analysis was performed to evaluate the long-term cost-effectiveness of LAM plus ADV combination therapy versus other nucleos $(t)$ ide analogs for the treatment of Chinese CHB patients.

Our study showed three key findings. First, in a basecase analysis the use of first-line treatment with ETV was the most cost-effective treatment for both HBeAg-positive and $\mathrm{HBeAg-negative} \mathrm{patients} \mathrm{relative} \mathrm{to} \mathrm{other} \mathrm{strategies.}$ ETV directly dominated LAM, ADV, and TBV due to its lower cost and higher efficacy in both cohorts. Although TDF and LAM plus ADV combination therapy generated higher LYS and QALYs than ETV monotherapy, the ICER of these approaches compared with ETV was beyond the WTP threshold of \$20,466/QALY gained. Second, we found that LAM monotherapy was never a cost-effective option for $\mathrm{CHB}$ patients because of its high viral resistance and nonresponse in long-term treatment, which might result in higher costs over the course of a lifetime. Another finding of our study was that basic rescue strategies had much better CER than alternative rescue treatments. Although potent combination rescue therapy was beneficial to improve health efficacy (LYS and QALYs), these strategies also presented greater economic burdens for Chinese patients. Hence, the basic rescue strategy would be the better option from an economic perspective. In addition, since the potent rescue strategy largely increased the lifetime costs of the other five nucleos(t)ide monotherapies considered, they were totally dominated by LAM plus ADV combination therapy, except for ETV and TDF in the HBeAg-negative group. However, the ICERs of ETV and TDF versus combination therapy were far higher than the WTP threshold of \$20,466/QALY gained, which indicated that the LAM plus ADV combination therapy would become the most cost-effective treatment, or even a cost-saving strategy for both $\mathrm{HBeAg-positive} \mathrm{and}$ $\mathrm{HBeAg-negative} \mathrm{groups} \mathrm{when} \mathrm{patients} \mathrm{directly} \mathrm{used} \mathrm{a} \mathrm{potent}$ rescue strategy.

This study is the first economic evaluation to assess the cost-effectiveness of LAM plus ADV combination therapy compared with other nucleos(t)ide analog monotherapies for treating $\mathrm{CHB}$ infections in Chinese patients. Since LAM plus ADV combination therapy was recommended for CHB patients in $2011,{ }^{25}$ a meta-analysis conducted in China showed that LAM plus ADV combination therapy can enhance anti-HBV agents and reduce viral resistance, which could permit long-term use. ${ }^{17}$ In addition, a clinical study conducted in India suggested that LAM plus ADV combination therapy was not inferior to ETV and TDF monotherapies, especially when treatment costs were taken into consideration, ${ }^{40}$ although this strategy remains controversial. A global multicenter, randomized and double-blind study found that LAM plus ADV combination therapy could not significantly suppress HBV DNA levels and reduce viral resistance, ${ }^{41}$ and thus some treatment guidelines do not recommend this strategy. ${ }^{4,5}$ The parameters of our study were derived from clinical trials based on Chinese populations, and the results of base-case analysis showed that LAM plus ADV combination therapy would not be the most cost-effective treatment for CHB patients compared with other nucleos $(\mathrm{t})$ ide analog monotherapies. These results are consistent with a previous study, which evaluated the cost-effectiveness of initial LAM plus ADV combination therapy and ETV in a scenario analysis and found that ETV monotherapy is a better option than combination therapy. ${ }^{42}$ Although LAM plus ADV combination therapy has greater clinical effectiveness, it also presents a greater economic burden for $\mathrm{CHB}$ patients. Moreover, the annual cost of LAM combined with ADV is higher than some nucleos(t)ide analog monotherapies, but unlike antiviral monotherapies, patients treated with drug combinations can develop multidrug resistance that requires more potent rescue strategies, such as ETV plus ADV or TDF combinations, to overcome initial combination therapy failure. Thus, even if the LAM plus ADV combination strategy is a cost-effective treatment for patients who directly received the potent rescue treatment (ETV plus ADV) after developing resistance to nucleos(t)ide analog monotherapies, its CER was still below that of ETV monotherapy followed by basic rescue therapy.

Several limitations of this analysis must be considered. First, due to the lack of long-term experience with different treatment strategies, the parameters in our model were mainly obtained from clinical trials conducted over 2-5 years, and this was particularly the case for LAM plus ADV combination therapy data. In China, there are no clinical trials of initial LAM plus ADV combination strategy that lasted for more than 3 years. Thus, a long-term randomized controlled trial (RCT) is needed to demonstrate the efficacy and safety of LAM plus ADV combination therapy. Moreover, future economic studies can incorporate results from long-term RCT or empirical data to further validate the model. Second, the annual costs of $\mathrm{CHB}$ and disease complications in China were obtained from a study published in 2009, which required the use of China health-care consumer price indices to adjust the costs to current levels.

In conclusion, the results of this analysis reveal that the long-term use of ETV remains a cost-effective strategy in Chinese CHB patients. However, LAM plus ADV combination 
therapy would be the optimal strategy in a scenario where potent rescue treatment is directly administered for patients with prior nucleos $(\mathrm{t})$ ide analog monotherapy failure.

\section{Acknowledgment}

This study was funded by National Natural Science Foundations of China (grant numbers 81302493 and 71573059). The funding agreement ensured the authors' independence in designing the study, interpreting the data, writing, and publishing the report.

\section{Disclosure}

The authors report no conflicts of interest in this work.

\section{References}

1. World Health Organization. Guidelines for the prevention, care and treatment of persons with chronic hepatitis B infection. Geneva, Switzerland: WHO; 2015. Available from: http://www.who.int/hiv/ pub/hepatitis/hepatitis-b-guidelines/en/. Accessed June 29, 2015.

2. Chinese Society of Hepatology and Chinese Society of Infectious Disease, Chinese Medical Association. [The guideline of prevention and treatment for chronic hepatitis B] (2010 version). Chin J Epidemiol. 2011;32(4):405-415. Chinese

3. Chen CJ, Yang HI, Iloeje UH. Hepatitis B virus DNA levels and outcomes in chronic hepatitis B. Hepatology. 2009;49(5 Suppl):S72-S84.

4. Liaw YF, Kao JH, Priatvisuth T, et al. Asian-Pacific consensus statement on the management of chronic hepatitis B: a 2008 update. Hepatol Int 2008;2:263-283.

5. Lok AS, McMahon BJ. Chronic hepatitis B: update 2009. Hepatology. 2009;50(3):661-662

6. European Association for the Study of the Liver. EASL clinical practice guidelines: management of chronic hepatitis B virus infection. $J$ Hepatol. 2012;57(1):167-185.

7. Yao GB, Zhu M, Cui ZY, Wang BE, Yao JL, Zeng MD. A 7-year study of lamivudine therapy for hepatitis B virus e antigen-positive chronic hepatitis B patients in China. J Dig Dis. 2009;10(2):131-137.

8. Zeng MD, Mao YM, Yao GB, et al. Five years of treatment with adefovir dipivoxil in Chinese patients with HBeAg-positive chronic hepatitis B Liver Int. 2012;32(1):137-146.

9. Hou JL, Yin YK, Xu DZ, et al. Telbivudine versus lamivudine in Chinese patients with chronic hepatitis B: Results at 1 year of a randomized, double-blind trial. Hepatology. 2008;47(2):447-454.

10. Jia JD, Hou JL, Yin YK, et al. Two-year results of a phase III comparative trial of telbivudine vs lamivudine in Chinese patients. Hepatology. 2007;46(Suppl 1):189.

11. Zhuang H, Weng XH. Development and management of drug resistance to nucleoside/nucleotide analogues in patients with chronic hepatitis B Chin J Hepatol. 2013;21:15-22.

12. Tujios SR, Lee WM. Update in the management of chronic hepatitis B. Curr Opin Gastroenterol. 2013;29(3):250-256.

13. Chen EQ, Wang LC, Lei J, Xu L, Tang H. Meta-analysis: adefovir dipivoxil in combination with lamivudine in patients with lamivudineresistant hepatitis B virus. Virol J. 2009;6:163.

14. Wang M, Yuan L, Qiao B, Li Y. Two rescue therapies in lamivudineresistant patients with chronic hepatitis B in the central China: adefovir monotherapy and adefovir plus lamivudine. Virus Genes. 2014;48(1): 32-37.

15. Ha M, Zhang G, Diao S, et al. Rescue therapy for lamivudine-resistant chronic hepatitis B: adefovir monotherapy, adefovir plus lamivudine or entecavir combination therapy. Intern Med. 2012;51(12): $1509-1515$.
16. Patterson SJ, Angus PW. Post-liver transplant hepatitis B prophylaxis: the role of oral nucleos(t)ide analogues. Curr Opin Organ Transplant. 2009;14(3):225-230.

17. Liu F, Wang X, Wei F, et al. Efficacy and resistance in de novo combination lamivudine and adefovir dipivoxil therapy versus entecavir monotherapy for the treatment-naive patients with chronic hepatitis B: a meta-analysis. Virol J. 2014;11:59.

18. Yu JH, Shi JP, Wu J, et al. Efficacy and safety of lamivudine plus adefovir combination therapy and entecavir monotherapy for chronic hepatitis B patients. Chin J Hepatol. 2011;19:88-92.

19. Ma XJ, Chen XP, Chen XF, et al. Efficacy of lamivudine and adefovir de novo combination therapy or after monotherapy in chronic hepatitis B patients. Chin J Hepatol. 2012;20:98-102.

20. Zhang JC. De novo combination therapy with lamivudine and adefovir dipivoxil versus entecavir monotherapy naive chronic hepatitis B patients with high viral loads. Chin J Clin Infect Dis. 2012;5: $142-144$.

21. Ren N, Yan J, Cai HD, Wu L. The observation of 96-weeks efficacy of lamivudine plus adefovir combination initial therapy for HBeAgpositive chronic hepatitis B. Int J Virol. 2012;19:113-117.

22. Yan J, Chen CR, Zhu YJ, et al. Efficacy and economic analysis of lamivudine plus adefovir dipivoxil de-novo and optimize combination therapy of 144 weeks for chronic hepatitis B patients. Int J Epidemiol Infect Dis. 2013;40:38-42.

23. Wang J, Shi JP, Zhu MF, Chen GY, Liu J, Zhou X. The efficacy and safety comparison between nucleoside (acid) analogue initial combination and monotherapy in the treatment of chronic hepatitis B for 144 weeks. Chin J Exp Clin Virol. 2014;28:82-84.

24. Wang LC, Chen EQ, Cao J, et al. De novo combination of lamivudine and adefovir versus entecavir monotherapy for the treatment of naive $\mathrm{HBeAg}$ negative chronic hepatitis B patients. Hepatol Int. 2011;5:671-676.

25. Expert committee of combination treatment for chronic hepatitis B. Expert consensus of combination treatment for chronic hepatitis B. Chin J Hepatol. 2012;4:39-46.

26. National Bureau of Statistics of China. Available from: http://data.stats gov.cn/easyquery.htm?cn=C01. Accessed June 29, 2015.

27. Wu B, Li T, Chen HF, Shen JF. Cost-effectiveness of nucleoside analog therapy for hepatitis B in China: a Markov analysis. Value Health. 2010; 13(5):592-600.

28. He J, Bowen JM, Xie F, Goeree R. Cost-effectiveness analysis of antiviral treatments for $\mathrm{HBeAg}$-positive chronic hepatitis B in Canada. Value Health. 2012;15(6):894-906.

29. Mommeja-Marin H, Mondou E, Blum MR, Rousseau F. Serum HBV DNA as a marker of efficacy during therapy for chronic HBV infection: analysis and review of the literature. Hepatology. 2003;37: 1309-1319.

30. Buti M, Brosa M, Casado MA, Rueda M, Esteban R. Modeling the cost-effectiveness of different oral antiviral therapies in patients with chronic hepatitis B. J Hepatol. 2009;51:640-646.

31. Chen L. A cost-effectiveness study on Avarbose to treat type 2 diabetes. China Master's Theses Full-Text Database 2008. Available from: http://d.wanfangdata.com.cn/Thesis/D446438. Accessed June 29, 2015.

32. The team of pharmacoeconomic evaluations. [China Guidelines for Pharmacoeconomic Evaluations]. Chin J Pharm Econ. 2010;5:5-43. Chinese.

33. The prices of Chinese Medicine. Available from: http://www.zgyyjgw. com/front/cn/retailPrice. Accessed June 29, 2015.

34. Levy AR, Kowdley KV, Iloeje U, et al. The impact of chronic hepatitis B on quality of life: a multinational study of utilities from infected and uninfected persons. Value Health. 2008;11(3):527-538.

35. Claxton K, Sculpher M, McCabe C, et al. Probabilistic sensitivity analysis for NICE technology assessment: not an optional extra. Health Econ. 2005;14(4):339-347.

36. Lavanchy D. Hepatitis B virus epidemiology, disease burden, treatment, and current and emerging prevention and control measures. J Viral Hepat. 2004;11:97-107. 
37. Kowdley KV. The cost of managing chronic hepatitis B infection a global perspective. J Clin Gastroenterol. 2004;38:132-133.

38. Zhang Y, Lian JQ, Li Y, et al. Telbivudine plus adefovir therapy for chronic hepatitis B patients with virological breakthrough or genotypic resistance to telbivudine. Eur J Gastroenterol Hepatol. 2013;25: 814-819.

39. Lee YB, Lee JH, Choi WM, et al. Efficacy of adefovir-based combination therapy for patients with Lamivudine- and entecavir-resistant chronic hepatitis B virus infection. Antimicrob Agents Chemother. 2013; 57:6325-6332.

40. Jayakumar R, Joshi YK, Singh S. Laboratory evaluation of three regimens of treatment of chronic hepatitis B: tenofovir, entecavir and combination of lamivudine and adefovir. J Lab Physicians. 2012;4: $10-16$.

41. Sung JJ, Lai JY, Zeuzem S, et al. Lamivudine compared with lamivudine and adefovir dipivoxil for the treatment of HBeAg-positive chronic hepatitis B. J Hepatol. 2008;48:728-735.

42. Veenstra DL, Sullivan SD, Clarke L, et al. Cost-effectiveness of entecavir versus lamivudine with adefovir salvage in $\mathrm{HBeAg}$-positive chronic hepatitis B. Pharmacoeconomics. 2007;25:963-977.

43. Wu GC, Zhou WP, Zhao YR, et al. Study on the natural history of chronic hepatitis B. Chin J Hepatol. 2002;10:46-48.

44. Huang H, Zhu CW, Yu XF, Wang GS, Wang JY. The development of cirrhosis in Chinese patients with chronic hepatitis B. Hepatol Int. 2007;6:437-440.

45. Xu B, Hu DC, Rosenberg DM, et al. Chronic hepatitis B: a long-term retrospective cohort study of disease progression in Shanghai. Chin J Gastroenterol Hepatol. 2003;18(12):1345-1352.

46. Chen YC, Chu CM, Yeh CT, Liaw YF. Natural course following the onset of cirrhosis in patients with chronic hepatitis B: a long-term follow-up study. Hepatol Int. 2007;1(1):267-273.

47. Hui AY, Chan HL, Leung NW, Hung C, Chan FK, Sung JJ. Survival and prognostic indicators in patients with hepatitis B virus-related cirrhosis after onset of hepatic decompensation. J Clin Gastroenterol. 2002;34(5):569-572.

48. Wang SB, Wang JH, Chen J, Giri RK, Chen MH. Natural history of liver cirrhosis in south China based on a large cohort study in one center: a follow-up study for up to 5 years in 920 patients. Chin Med J. 2012;125(12):2157-2162.

49. Lo CM, Fan ST, Liu CL, Chan SC, Wong J. The role and limitation of living donor liver transplantation for hepatocellular carcinoma. Liver Transpl. 2004;10(3):440-447.
50. Wu TJ, Chan KM, Chou HS, et al. Liver transplantation in patients with hepatitis B virus-related hepatocellular carcinoma: the influence of viral characteristics on clinical outcome. Ann Surg Oncol. 2013;20(11): 3582-3590.

51. Yao GB, Ren H, Xu DZ, et al. Results of 3 years of continuous entecavir treatment in nucleos(t)ide-naive chronic hepatitis B patients. Chin J Hepatol. 2009;17(12):881-886.

52. Chen EQ, Zhou TY, Liu L, Liu C, Lei M, Tang H. A comparison of treatment with adefovir and entecavir for chronic hepatitis B in China: The 2-year results of a prospective study. Hepat Mon. 2011;11(1):27-31.

53. Yuen MF, Seto WK, Fung J, Wong DK, Yuen JC, Lai CL. Three years of continuous entecavir therapy in treatment-naive chronic hepatitis B patients: viral suppression, viral resistance, and clinical safety. Am J Gastroenterol. 2011;106:1264-1271.

54. Hou JL, Gao ZL, Xie Q, et al. Tenofovir disoproxil fumarate vs adefovir dipivoxil in Chinese patients with chronic hepatitis B after 48 weeks: a randomized controlled trial. J Viral Hepat. 2015;22:83-91.

55. Lee S, Heathcote EJ, Sievert W, et al. Tenofovir disoproxil fumarate (TDF) versus adefovir dipivoxil (ADV) in Asians with HBeAg-positive and HBeAg-negative chronic hepatitis B participating in studies 102 and 103 [poster no. 980]. Poster presented at: 59th Annual Meeting of the American Association for the Study of Liver Diseases, October 31-November 4, 2008, San Francisco, CA.

56. Snow-Lampart A, Chappell B, Curtis M, et al. Week 96 resistance surveillance for $\mathrm{HBeAg}$ positive and negative subjects with chronic $\mathrm{HBV}$ infection randomized to receive tenofovir DF $300 \mathrm{mg}$ QD [poster no. 977]. Poster presented at: 59th Annual Meeting of the American Association for the Study of Liver Diseases, October 31-November 4, 2008, San Francisco, CA.

57. Hu M, Chen W. Assessment of total economic burden of chronic hepatitis B (CHB)-related diseases in Beijing and Guangzhou, China. Value Health. 2009;12(Suppl 3):S89-S92.

58. Gao Q. Economic analysis for liver and renal transplant in a transplant center. China Master's Theses Full-Text Database 2007. Available from: http://d.wanfangdata.com.cn/Thesis/Y1326546. Accessed June $29,2015$.

59. National Bureau of Statistics of China. Available from: http://www. stats.gov.cn/tjsj/pcsj/rkpc/6rp/indexch.htm. Accessed June 29, 2015.

60. Yao GB, Chen CW, Lu WL, et al. Efficacy and safety of entecavir compared to lamivudine in nucleoside-naive patients with chronic hepatitis B: a randomized double-blind trial in China. Hepatol Int. $2008 ; 2: 136$
Drug Design, Development and Therapy

\section{Publish your work in this journal}

Drug Design, Development and Therapy is an international, peerreviewed open-access journal that spans the spectrum of drug design and development through to clinical applications. Clinical outcomes, patient safety, and programs for the development and effective, safe, and sustained use of medicines are a feature of the journal, which

\section{Dovepress}

has also been accepted for indexing on PubMed Central. The manuscript management system is completely online and includes a very quick and fair peer-review system, which is all easy to use. Visit http://www.dovepress.com/testimonials.php to read real quotes from published authors. 